\title{
Insect Pollinators of Carrot Grown for Seed Production in Kashmir Valley
}

\author{
Muneer Ahmad*, S.S. Pathania and Sushil Kumar \\ Division of Entomology, Sher-e-Kashmir University of Agricultural Sciences and Technology \\ Shalimar Srinagar, Kashmir, J\&K 190025 \\ *Corresponding author
}

\begin{abstract}
A B S T R A C T

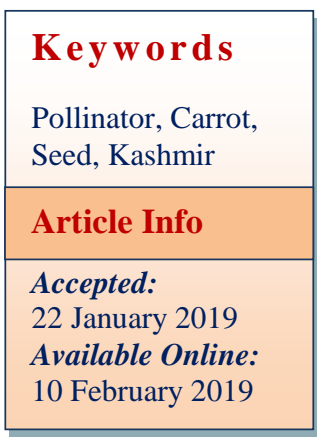

The course of observation at Habak Urban park of SKUAST- Kashmir valley during 201618 , on the occurrence and pollinating activities of insects on carrots grown for seed, 11 species representing two orders, were collected. Most numerous in species were the hymenopterans families and the dipterous families Syrphidae. Most numerous in individuals were the dipterous families Syrphidae. Families and super families represented by the most efficient pollinators were Apoidea, Syrphidae. Abundance time's efficiency was used as a pollination index for each species was recorded. On this basis the most important pollinators were recorded as Apis mellifera (21.30\%), Apis cerana (19.74\%). Honey bees (Apis mellifera L.) were efficient pollinators, on carrot flowers. In most areas a combination of honey bee colonies adjacent to carrot seed fields and elimination of competing bloom may be the most practical method of increasing carrot pollination. The highest see yield and germination were recorded under open pollination condition as compared to the enclosed condition.
\end{abstract}

\section{Introduction}

Carrot (Daucus carota L.), a cool season crop, is grown during winter in tropical and subtropical climate. It is one of the most ancient and now one of the most popular vegetables (Bose and Som, 1990). The carrot is a biennial plant in the umbellifer family Apiaceae. At first, it grows a rosette of leaves while building up the enlarged taproot. Fast-growing cultivars mature within three months (90 days) of sowing the seed, while slower-maturing cultivars are harvested four months later (120 days). The roots contain high quantities of alpha- and beta-carotene, and are a good source of vitamin $\mathrm{K}$ and vitamin $\mathrm{B} 6$, but the belief that eating carrots improves vision. Carrot is grown in vegetable belts of Kashmir valley.

There are two varieties red and black which are grown in Kashmir. The seed production is mainly dependent on insect pollinator for cross pollination. Insect pollinators were proved to be essential for commercial seed production (Hawthorn et al., 1960) as 85\% increase in yield was obtained with honeybees' pollination. Pankratova (1964) found that plots visited by insects produced 15 times more number of seeds and ten times 
more weight of seed as compared to that of plants covered with muslin cloth.

\section{Materials and Methods}

The Present investigations were carried in Habak urban park of Division of Vegetable science SKUAST-Kashmir during 201618.The Pollinator fauna and their abundance was recorded. The Crop for seed production was transplanted in December. The experiment was conducted in Randomized block design.

The activities of the pollinators were recorded at different day intervals. Studies on diurnal activity and foraging behavior of different insect pollinators in carrot were carried out in the crop bloom season. The impact of insect pollination on quantitative as well as qualitative was recorded. The Photographic digitization was done, in order to have complete list of pollinators available to the farming community of Kashmir valley.

\section{Results and Discussion}

The trial was laid at Urban park Habak Srinagar during 2016-2018 Rabi in collaboration with division of vegetable science SKUAST-K. The carrot bloom was observed whole of the season for insect visitors. The Insect visitors were collected, preserved and identified total eleven (12) insect pollinators were recorded in carrot bloom in Kashmir. Out of these 4 pollinators belonged to order Hymenoptera, 7 from order Diptera and one ant as accidental pollinator (Table 1). Among all the mean pollinator fauna Apis mellifera was the most dominant pollinator constituting $21.31 \%$ followed by Apis cerana which constituted $19.74 \%$.The least $0.52 \%$ of Musca domestica as accidental pollinators were also recorded. The list of photographs is listed from 1 to 11 . The insect pollinators are Apis mellifera, Apis Cerana,
Eristalinus arbustorum, Eristalinus taeniops, Eristalis lineate, Lasioglossum marginatum, Adrena sp., Eristalis tenax, Sphaerophoria bengalensis Eristallis sp and Musca domestica

Perusal of data on various insect visitors on carrot flowers at different day hours revealed that a total of 11 insect species belonging to orders Hymenoptera and Diptera were recorded during the study period (Table 1).

Observations on diurnal abundance of different insect visitors on carrot bloom at different day hours presented in table 1 indicated that most of the insect visitors were active throughout the day. The mean insect visitor population (Nos of bees $/ \mathrm{m}^{2} / 5$ minute) over different day hours on carrot flowers varied from 0.33 (Musca domestica) to 9.08 (Apis mellifera) (Table 2).

The Highest population (12.00 nos of insect visitors $/ \mathrm{m} 2 / 5$ minute) was observed at 10 AM. The highest mean number of insect visitors 9.08 Apis melifera $/ \mathrm{m}^{2} / 5$ minutes were recorded during the full reading hours followed by 8.24 visitors of Apis Cerana $/ \mathrm{m}^{2} / 5$ minute and the least 0.33 visitors of Musca domestica/m2/5 minute was recorded.

The data presented in table 3 shows that umbels left for open pollination resulted in significantly higher seed set than those excluded from insect visitation. The Net caged umbels had $15.00 \%$ seed set and while those left for open pollination resulted in $95.66 \%$. Number of seeds produced per umbel also varied significantly. Caged umbel with net produced 744 seeds/umbel and as compared to 1317 seeds/capsule in case of umbels left for open pollination. Similarly, seed germination percentage in closed condition shows $(10.00 \%)$ while as in open condition $92.66 \%$ germination was recorded. 
Table.1 Insect pollinator fauna of carrot bloom in Kashmir

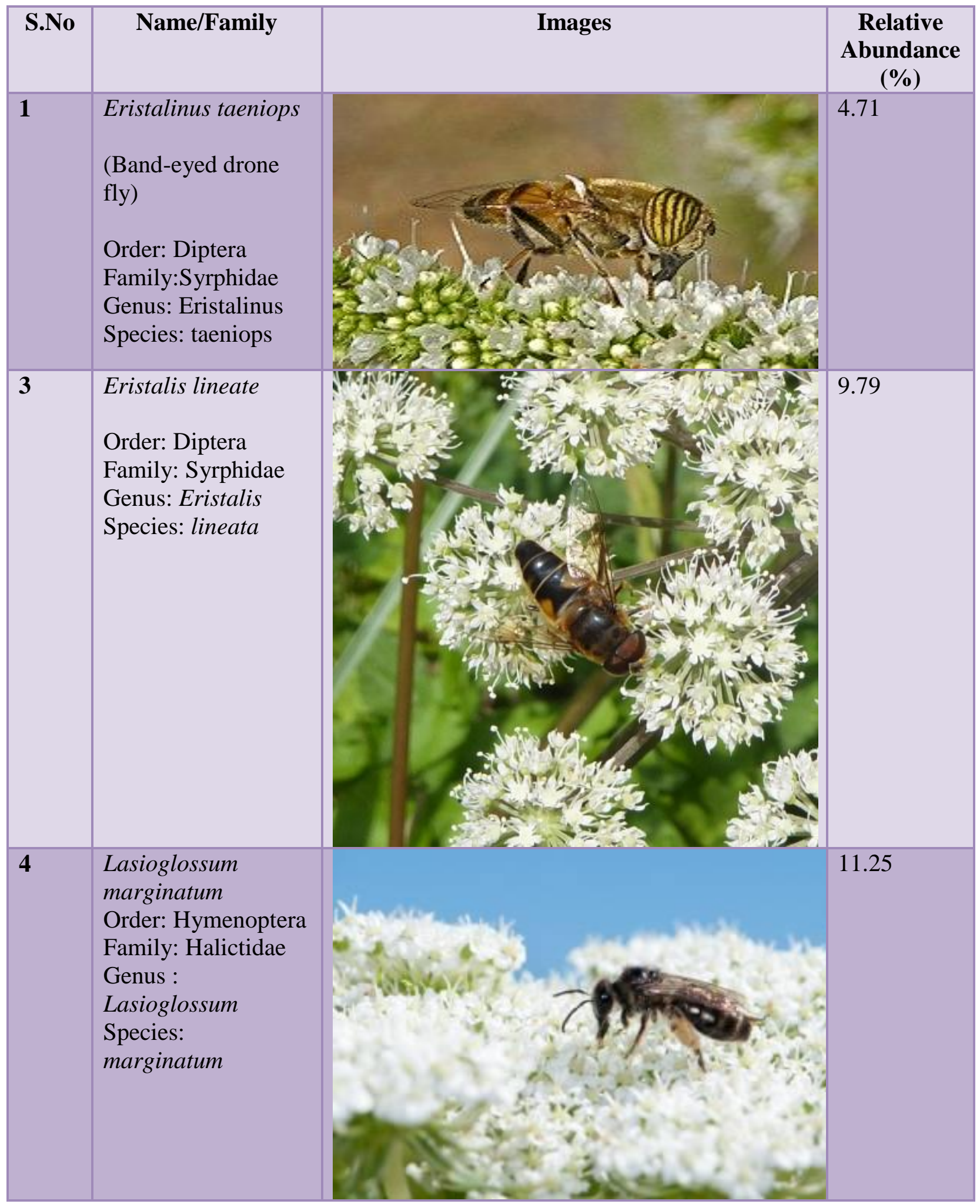




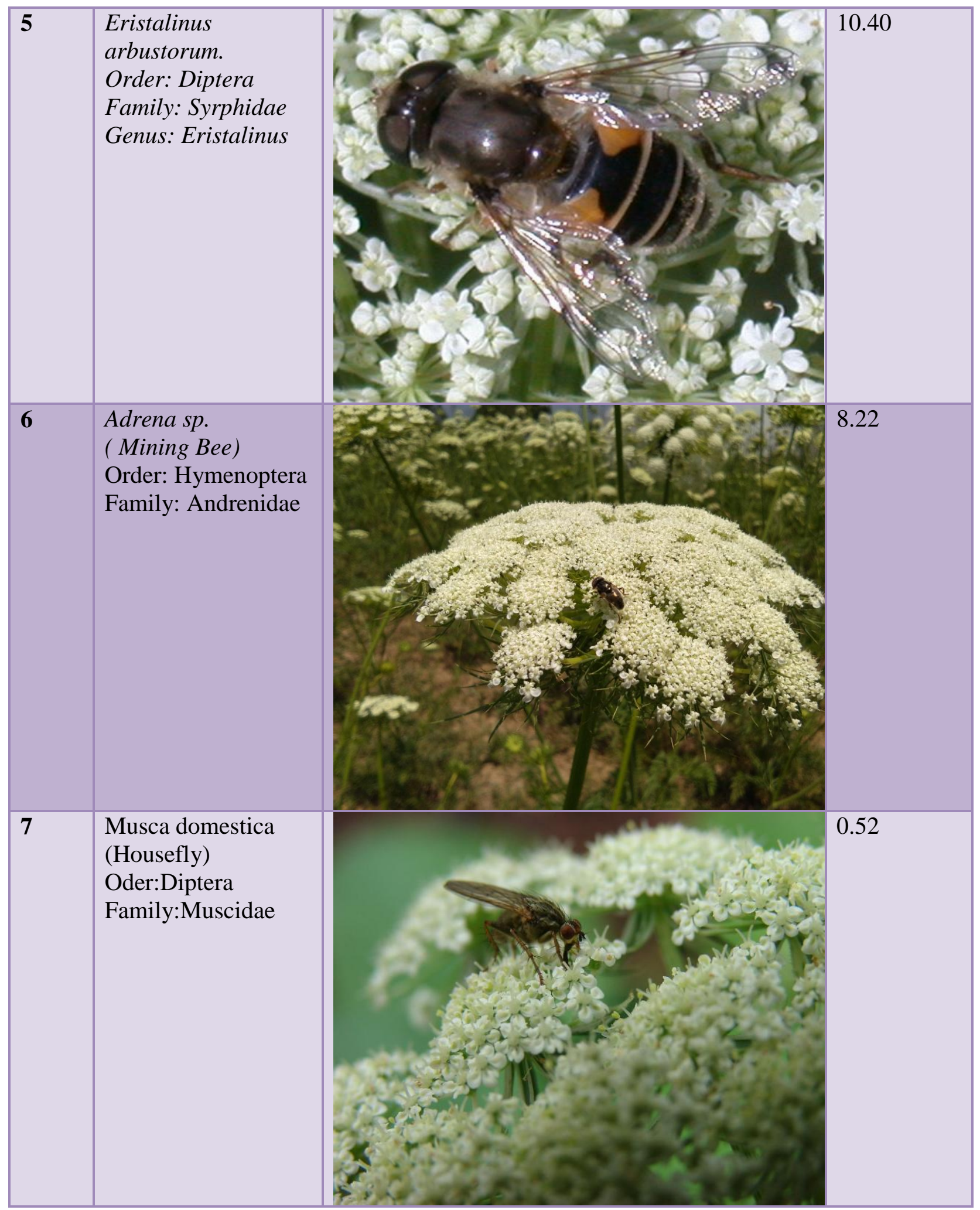




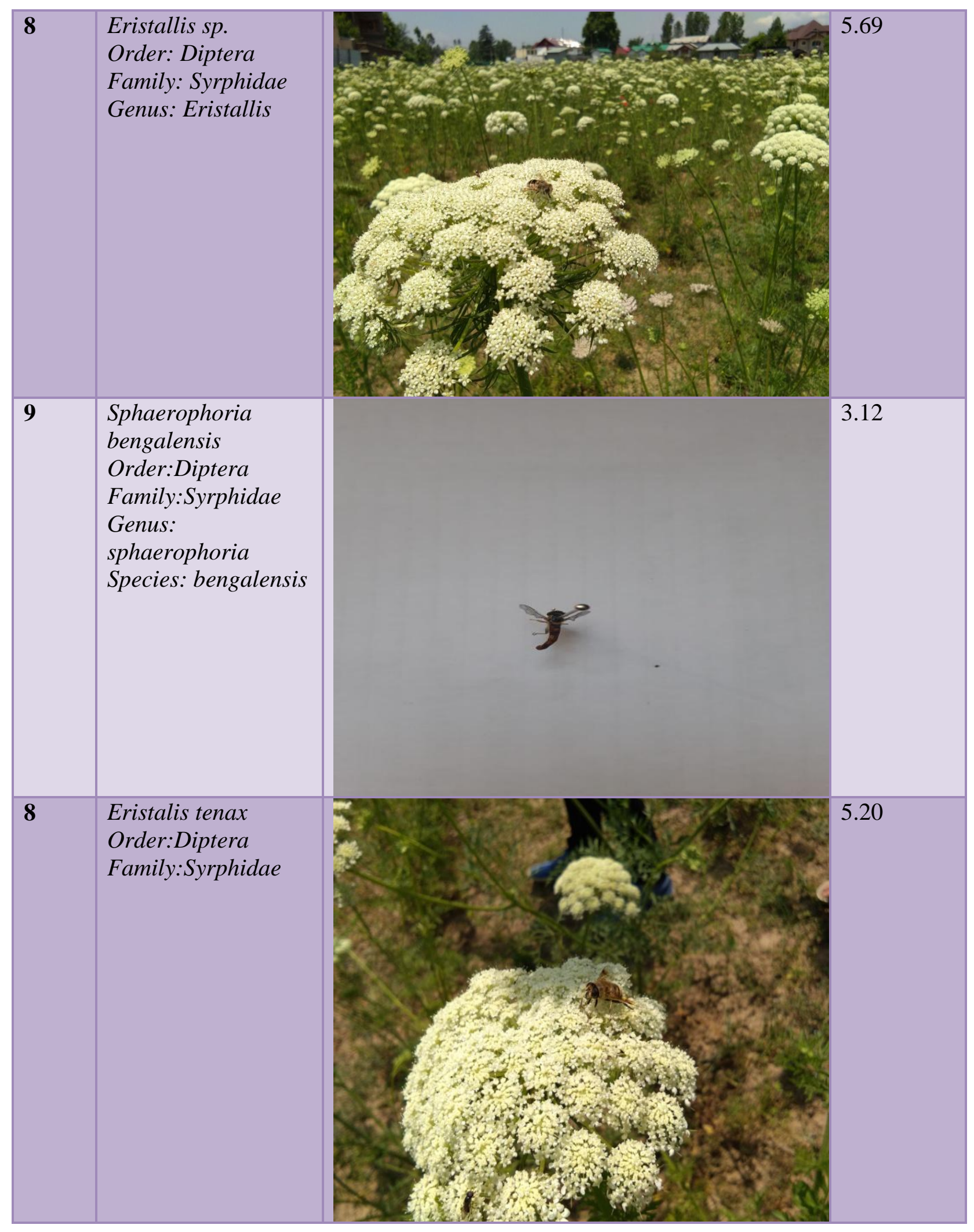




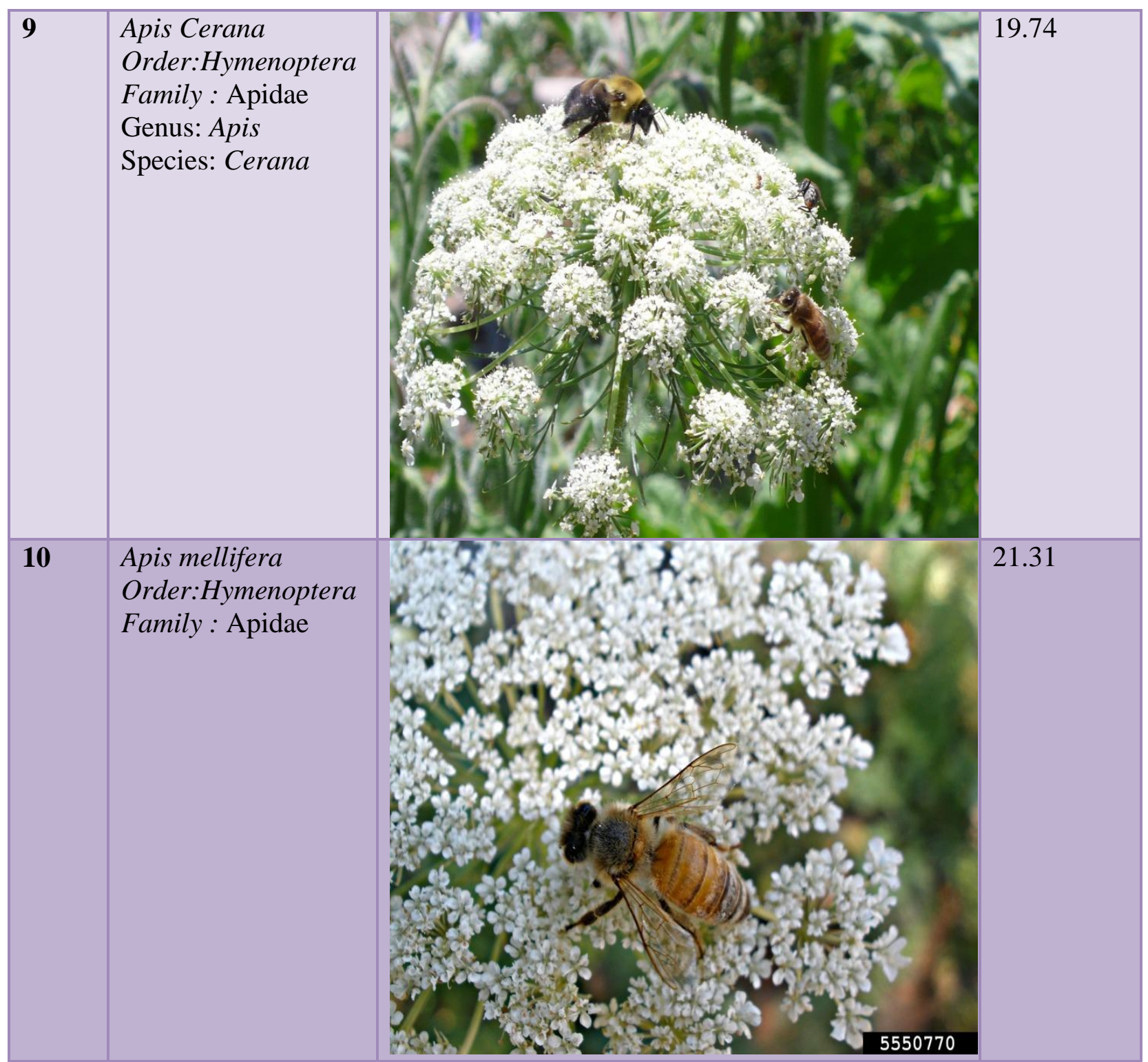

Table.2 Abundance of insect visitors on carrot bloom on different time intervals in Kashmir

\begin{tabular}{|l|c|c|c|c|c|}
\hline Insect Visitor & \multicolumn{4}{|c|}{ Population of Insect visitors/m2/5 minutes } & \multirow{2}{*}{ Mean } \\
\hline Apis cerana & $\mathbf{7}$ am & $\mathbf{1 0}$ am & $\mathbf{1 2}$ noon & $\mathbf{2 ~} \mathbf{~ p m}$ & \\
\hline Apis mellifera & 8.33 & 10.33 & 4.33 & 10.00 & 8.24 \\
\hline Eristalis tenax & 3.66 & 12.00 & 9.33 & 11.33 & 9.08 \\
\hline Sphaerophoria bengalensis & 2.00 & 6.00 & 5.33 & 4.33 & 4.41 \\
\hline Eristallis sp. & 3.00 & 4.00 & 3.33 & 2.00 & 3.08 \\
\hline Musca domestica & 3.33 & 6.33 & 5.33 & 4.00 & 4.74 \\
\hline Adrena sp. & 1.00 & 0.22 & 0.11 & 0.00 & 0.33 \\
\hline Eristalinus arbustorum & 2.00 & 7.00 & 6.00 & 5.00 & 5.00 \\
\hline Lasioglossum marginatum & 3.33 & 7.66 & 6.33 & 5.33 & 5.66 \\
\hline Eristalis lineate & 2.00 & 8.33 & 7.00 & 6.00 & 5.83 \\
\hline Eristalinus taeniops & 3.00 & 7.33 & 7.00 & 6.00 & 5.83 \\
\hline
\end{tabular}


Table.3 Effect of pollination treatments on yield components of carrot in Kashmir

\begin{tabular}{|l|c|c|c|}
\hline \multicolumn{1}{|c|}{ Parameter } & $\begin{array}{c}\text { No Pollination } \\
\text { (Enclosed) }\end{array}$ & $\begin{array}{c}\text { Insect Pollination } \\
\text { (Open pollination) }\end{array}$ & C.D at 5\% \\
\hline Seed set(\%) & 15.00 & 95.66 & 7.35 \\
\hline No. of seeds/umbel & 744 & 1317 & 6.23 \\
\hline Germination \% & 10.00 & 92.66 & 8.23 \\
\hline
\end{tabular}

Apis cerana and Apis mellifera constituted major pollinators which fall in line with the results obtained by Jadhav and Ajiri (1981) and Mohan Rao and Suryanarayana (1989). Hence it is observed that pollination in carrot is a necessary input and the insect fauna has great role in proper pollination and seed set.

\section{References}

Abrol, D.P. (1997) "Impact of insect pollination on carrot seed production", Insect Environ., 3, 61.

Baydar, H. and Gurel, F. 1999. The effect of honey bees on cross pollination and hybrid seed production in sesamum. Turkish Journal of field crops 4(1):2124.

Bohart, G.E. and Nye, W.P. (1968) "Insect pollinators of carrot in Utah", Utah Agri. Expt. Sta. Bull., 419, 16.

Bose, T.K. and Som, M.G. (1990) "Vegetable crops in India", Kalyani Publishers, Naya Prakash, India, p. 409.

Chopra, R.N. (1933) "Indigenous drugs of India”, The Art Press, Calcutta, p. 3, 61.

Free, J.B. 1993. Insect pollination of crops. Second Edition Academic press, London.

Goyal, N.P., Singh, M. and Kandoria, J.L. (1989) "Role of insect pollination in seed production of carrot, Daucus carota Linn.” Ind. Bee J., 51, 89-93.

Hawthorn, R.L., Bohart, G.E., Toole, E.H., Nye, W.P. and Levin, M.D. (1960) "Carrot seed production as affected by insect pollination", Bull. Utah Agric. Exp. Sta., 422, 18.

Jadhav, L.D. and Ajri, D.S 1981.Insect pollinators of onion (Alium cepa L.) in Ahmadnagar district of Maharashtra, India. Indian Bee Journal, 43: 409.

Kirtikar, K.R. and Basu, B.D. (1935) "Indian medicinal plants", Lolit Mohan Basu, Allahabad, p. 61.

Misra, R.C., Kumar, T., Veeresh, G.K., Shaankar, R.U. and Ganeshaiah, K.N. (1993) "Status of research in pollination biology in Himachel Pradesh", Proc. Intern. Symp. Poll. in Tropics, August 8-13, India, 279 - 295.

Mohan Rao, G and Suryanarayana, M.C. 1989. Effect of honey bee pollination on seed yield in onion (Allium cepa L). Indian Bee Journal, 51(1); 9-11.

Pankratova, E.P. (1964) "Data on the biology of blossoming and pollination of carrots", Dokl. TSKhA, 36, 118-123.

Sihag, R.C. 1986. Insect Pollination increases seed production in cruciferous and umbelliferous crops. Journal of Apiculture Research, 25: 121-126.

\section{How to cite this article:}

Muneer Ahmad, S.S. Pathania and Sushil Kumar. 2019. Insect Pollinators of Carrot Grown for Seed Production in Kashmir Valley. Int.J.Curr.Microbiol.App.Sci. 8(02): 2965-2971. doi: https://doi.org/10.20546/ijcmas.2019.802.346 